\title{
Treatment of metastatic non-small cell lung cancer with NY-ESO-1 specific TCR engineered-T cells in a phase I clinical trial: A case report
}

\author{
YAN XIA ${ }^{1-3^{*}}$, XIAOPENG TIAN ${ }^{3 *}$, JUNTAO WANG $^{2}$, DONGJUAN QIAO ${ }^{2}$, XIANHAO LIU $^{1}$, \\ LIANG XIAO ${ }^{1}$, WENLI LIANG ${ }^{1}$, DONGCHENG BAN ${ }^{2}$, JUNJUN CHU ${ }^{3}$, JIAMING YU ${ }^{3}$, \\ RONGFU WANG $^{4}$, GENG TIAN $^{1}$ and MINGJUN WANG ${ }^{2}$
}

\begin{abstract}
${ }^{1}$ Department of Oncology, Shenzhen Second People's Hospital, The First Affiliated Hospital of Shenzhen University, Shenzhen, Guangdong 518035; ${ }^{2}$ Department of Research and Development, Shenzhen Institute for Innovation and Translational Medicine, Shenzhen, Guangdong 518120; ${ }^{3}$ Zhongshan School of Medicine, Sun Yat-Sen University, Guangzhou, Guangdong 510080, P.R. China; ${ }^{4}$ Center for Inflammation and Epigenetics,

Houston Methodist Research Institute, Houston, TX 77030, USA
\end{abstract}

Received February 13, 2018; Accepted July 27, 2018

DOI: $10.3892 / 01.2018 .9534$

\begin{abstract}
This article presented a case of a human leukocyte antigen (HLA)-A2-positive patient with advanced cancer/testis antigen New York esophageal squamous cell carcinoma-1 (NY-ESO-1) expressing lung adenocarcinoma (LADC) who received adoptive cell therapy of $\mathrm{T}$ cell receptor engineered-T cells (TCR-T cells) targeting the cancer-testis antigen NY-ESO-1. The appropriate clinical and laboratory assessments were conducted to investigate the safety and efficacy of this therapy for this lung cancer patient. The patient had a clinical response to and was well-tolerated with this therapy in the clinical trial. In addition, a preliminary evaluation of the safety of NY-ESO-1 TCR-T cell therapy was performed in four patients with non-small cell lung cancer (NSCLC) enrolled in a clinical trial. It was well-tolerated and did not observe any serious adverse events post-infusion. Fever, anemia, and a decrease in white blood cell count were common adverse events, which were likely due to the TCR-T cell therapy. Two patients
\end{abstract}

Correspondence to: Dr Mingjun Wang, Department of Research and Development, Shenzhen Institute for Innovation and Translational Medicine, Building C2, Life Science Industrial Park, Shenzhen International Biological Valley, Kwai Chung, Dapeng, Shenzhen, Guangdong 518120, P.R. China

E-mail: mingjunw429@163.com

Dr Geng Tian, Department of Oncology, Shenzhen Second People's Hospital, The First Affiliated Hospital of Shenzhen University, 3002 Sungang West Road, Shenzhen, Guangdong 518035, P.R. China E-mail: tiangeng_tg666@163.com

*Contributed equally

Key words: adoptive cell therapy, non-small cell lung cancer, lung adenocarcinoma, NY-ESO-1, TCR-engineered T cell had clinical responses to NY-ESO-1 TCR-T cell therapy, including the 44-year-old female patient with LADC, who achieved a short-term partial response for 4 months, improved in Karnofsky performance status, and had a recovery of drug sensitivity. This suggests that TCR-T cell therapy targeting NY-ESO-1 antigen may be beneficial for HLA-A2-positive late-stage patients with NY-ESO-1-expressing NSCLC.

\section{Introduction}

Lung cancer is a leading cause of cancer deaths worldwide (1), while non-small cell lung cancers (NSCLCs) accounting for $>80 \%$ of all lung cancer cases $(2,3)$. NSCLC can be categorized into three major histologic subtypes: Lung adenocarcinoma (LADC), lung squamous cell carcinomas (LSCC) and large cell lung cancer (LCLC). Among them, LADC is the most commonly occurring subtype (3). Patients with advanced NSCLC (stage IIIb and IV) have no surgical treatment options available and will be treated with systemic therapeutics, including radiation therapy, chemotherapy, target therapy and immunotherapy (3). However, chemotherapy and radiation therapy have high incidences of severe side effects. The most of therapies targeted lung cancer mutatuion driver genes (such as mutations in EGFR, KRAS, HER2, BRAF, RET, ROS1 and ALK) have eventually failed due to drug resistance (4). Many clinical trials using immune checkpoint blockade therapy have shown impressive and durable clinical benefits in lung cancer, and in other human cancers (5-8). However, the majority of lung cancer patients fail to respond to the checkpoint immunotherapy (9). Therefore, new immunotherapeutic strategies are urgently needed for those who fail to respond to the immune checkpoint therapy. Recently, cancer-specific T cells have been further developed to eradicate cancer cells (10). Adoptive cell therapy (ACT) using cultured autologous tumor-infiltrating lymphocytes (TILs) can induce a clinical response in cancer patients, even in those who have previously experienced treatment failure with other immunotherapies $(11,12)$. However, 
it remains a challenge to generate tumor-reactive TILs from tumor tissues.

Genetic engineering enables the creation of $\mathrm{T}$ cells expressing chimeric antigen receptors (CARs) that recognize tumor membrane antigens, or T cell receptors (TCRs) recognizing tumor membrane and intracellular antigens presented by specific major histocompatibility complex (MHC) molecules $(10,13)$. These approaches redirect the antigen specificity of $\mathrm{T}$ cells for in vitro expansion, and thus help overcome practical barriers that limit the widespread use of TILs $(14,15)$. Notably, chimeric antigen receptor-engineered T cells (CAR-T cells) targeting B-cell lineage differentiation antigen CD19 have acheived impressive clinical response rates (16-18). A great effort has been made to use CAR-T immunotherapy to treat patients with solid cancers. However, such a CAR-T therapy has poor clinical response in solid tumor due to the tumor microenvironment and the lack of suitable cell-surface targets that specifically expressed on tumor cells (19).

Cancer specific antigens/targets, which are supposed to express in cancer cells but not in normal cells, play a vital role in a successful cancer immunotherapy. Unfortunately, there are few cancer specific antigens available as useful targets for immunotherapy in solid tumor. Cancer-testis antigens are identified as attractive immunotherapy targets in many cancers due to their high expression in a variety of malignant neoplasms, but lack of expression in normal adult tissues with the exception of normal testis. However, male germ cells do not express human leukocyte antigen (HLA) class I molecular, and thus are immunologically protected (20-22). Moreover, expression of some cancer-testis antigens in tumors could induce specific humoral and cellular immune responses in cancer patients $(21,23)$. A recent study shows that TCR-modified $\mathrm{CD}^{+} \mathrm{T}$ cells targeting cancer-testis antigen MAGE-A3 objectively respond to metastatic cancers, including metastatic cervical cancer, esophageal cancer, urothelial cancers and osteosarcoma (19). The cancer-testis antigen NY-ESO-1 is one of the most promising candidate targets for immunotherapy due to the strong associated immunogenicity (24-28). The clinical importance of NY-ESO-1 in T cell therapy has been supported from a case study that a patient with refractory melanoma treated with autologous NY-ESO-1-specific $\mathrm{CD}^{+}{ }^{+} \mathrm{T}$ cells stimulated with NY-ESO-1 peptide achieved a long-term complete remission (29). Subsequent studies using ACT with NY-ESO-1 TCR-engineered T cells (TCR-T cells) could effectively mediate tumor regression in melanoma and synovial cell sarcoma, as well as multiple myeloma with well tolerance $(13,14,30,31)$. However, the safety and efficacy of NY-ESO-1 TCR-T cells in lung cancer remain unknown.

NY-ESO-1 antigen is expressed in 11.8-21\% of NSCLCs $(25,32,33)$, and serum anti-NY-ESO-1 antibody has been detected in $13-20 \%$ patients with lung cancers $(34,35)$ and in $23 \%$ patients with NSCLC (35). NY-ESO-1 has already been shown as a promising target for cancer immunotherapy with good safety and efficiency $(13,30,31)$. Therefore, we choose the NY-ESO-1 as an ideal target for TCR-T cells in our study. In the present study, four patients with NSCLC enrolled in the clinical trial (NCT02457650) that aims at preliminarily evaluating the safety and feasibility of NY-ESO-1 TCR-T cell therapy for HLA-A2-positive patients with NY-ESO-1 antigen-expressing malignancies revealed well tolerance.
Here, we reported that a female patient with advanced LADC revealed a partial response (PR, 4 months) with NY-ESO-1 TCR-T cell therapy without evident toxicity.

\section{Patients and methods}

Patients and clinical trial design. Patients, aged one year and older, expressing HLA-A2 with NY-ESO-1 antigen-expressing solid tumors refractory to standard treatment, were enrolled into the present clinical trial. We recruited four subjects with NSCLC in our preliminarily study on TCR-T cell therapy. More than $30 \%$ of cells in patients' tumor specimen were stained with at least $>1+$ intensity for NY-ESO-1 antigen expression when immunohistochemical (IHC) staining was performed using anti-NY-ESO-1 monoclonal antibody (Santa Cruz Biotechnology, Inc., Dallas, TX, USA.). Staining intensity was graded as 1+, weak staining; 2+, moderate staining; and $3+$, strong staining. A lymphodepleting chemotherapy regimen prior to adoptive $\mathrm{T}$ cell infusion has been shown to dramatically enhance the persistence of the transferred cells and improve anticancer effects $(36,37)$. In addition, the lymphodepleting chemotherapy regimen may deplete Treg cells and other suppressive cells in the circulation and the tumor micro environment, thus enabling the survival and amplification of adoptively transferred $\mathrm{T}$ cells to achieve effective killing of cancer cells (38). In the current study, a lymphodepleting chemotherapy regimen consisting of cyclophosphamide (CTX; $30 \mathrm{mg} / \mathrm{kg} / \mathrm{d}$ for 2 days) and fludarabine (Flud; $25 \mathrm{mg} / \mathrm{m}^{2} / \mathrm{d}$ for 3 days) was purposed to be administrated to patients prior to the NY-ESO-1 TCR-T cell infusion. A previous study reported that the patients receiving a median of $5 \times 10^{10} \mathrm{~T}$ cells transduced with an anti-NY-ESO-1 TCR (range of 1.6 to $130 \times 10^{9}$ ) achieved objective clinical responses with good safety in metastatic synovial cell sarcoma and melanoma (14). In the current study, total $\mathrm{T}$ cells at a median of $7.16 \times 10^{9}$ cells (range of $1.67-10.60 \times 10^{9}$ cells, transfection rate between $36.6 \%$ and $96.6 \%$ ) were intravenously infused in one to three days with interleukin (IL)-2 (Beijing Shuanglu Pharmaceutical Co Lt., Beijing, China) administrated subcutaneously for the following consecutive 14 days (typically, 0.8-2.0 MIU/d) according to patient tolerance. This clinical trial was conducted in Shenzhen Second People's Hospital and approved by the Medical Ethics Committee of the Institutional Review Board of the Shenzhen Second People's Hospital. All procedures performed in studies involving human participants were in accordance with the ethical standards of the institutional and/or national research committee and meets the standards of the Declaration of Helsinki in its revised version of 1975 and its amendments of 1983, 1989, and 1996 [JAMA 1997; 277:925-926]. All patients enrolled in the trial provided written informed consent.

T cell transduction and quantitative real-time PCR analyses. Patient peripheral blood mononuclear cells (PBMCs) were collected via leukopheresis. Then, PBMCs were stimulated using $50 \mathrm{ng} / \mathrm{ml}$ anti-CD3 antibody (OKT3; Ortho-Biotech, Bridgewater, NJ, USA) and 300 IU recombinant IL-2 (Peprotech, UK), followed by transduction with retroviral vector carrying nucleic acid sequences encoding an HLA-A2 restricted TCR recognizing NY-ESO-1:157-165 
epitope $(30,39,40)$. The transduced cells were then expanded in vitro before being adoptively transferred as previously described (41). Clinical grade retroviral supernatants produced under good manufacturing practice (GMP) conditions were obtained from the Shenzhen Institute for Innovation and Translational Medicine (Shenzhen, China). IFN- $\gamma$ released by the TCR-T cells was measured based on recognition of tumor cell line Mel 624 (HLA-A2 ${ }^{+}$and NY-ESO-1 ${ }^{+}$), which had been established in the Surgery Branch, National Cancer Institute from resected tumors $(42,43)$ as described previously $(14,40)$. Co-incubation of TCR-T cells with Mel 586 (HLA-A2 and NY-ESO- $1^{+}$) was used as a negative control. Mel 624 or Mel 586 cells $\left(5 \times 10^{4}\right.$ cells/well) were seeded in 96-well cell culture plates with medium, respectively, and incubated overnight. The culture medium was replaced with fresh ones containing TCR-T cells. After co-incubation for $18 \mathrm{~h}, \mathrm{IFN}-\gamma$ released in supernatant was measured by enzyme-linked immunosorbent assay (ELISA). The persistence of NY-ESO-1 specific TCR-T cells in vivo was evaluated by quantitative real-time PCR of samples of whole blood at serial time-points before and after cell infusion. Genomic DNA was isolated from whole blood samples using QIAamp DNA blood midi kits (Qiagen, Inc., Valencia, CA, USA) and quantified by spectrophotometer. The qPCR analyses were performed as previously described (31,44-46) using ABI 7900HT Real-Time PCR System (Thermo Fisher Scientific, Inc., Waltham, MA, USA).

$T$ cell tracking and cytokine detection. The following antibodies (BD Biosciences, Franklin Lakes, NJ, USA) were used to identify T cells: CD4-PE, CD8-FITC, CD25-FITC, and CD28-PE. Flow cytometry was performed using a BD Accuri ${ }^{\mathrm{TM}}$ C6 personal flow cytometer (BD Biosciences) and data were analyzed using FlowJo software (Tree Star, Ashland, OR, USA). Cytokine secretion was evaluated by V-PLEX Human Cytokine 30-Plex kit with measurements by MESO QuickPlex SQ 120 (Meso Scale Discovery, Rockville, MD, USA).

\section{Results}

Patients and clinical assessment. A total of four HLA-A2-positive patients with NY-ESO-1+ ${ }^{+}$metastatic NSCLC received lymphodepleting chemotherapy and then were adoptively transferred with NY-ESO-1 TCR-T cells and coupled with systemic IL-2 administration. Clinical symptoms experienced by the patients and administration of total $\mathrm{T}$ cells were listed in Table I. It was revealed that co-incubation of TCR-T cells with Mel 624 cells induced the release of IFN- $\gamma$ at a median of $3,409 \mathrm{pg} / \mathrm{ml}$, compared to $<100 \mathrm{pg} / \mathrm{ml}$ in control. All patients with metastatic NSCLC treated with given standard treatments experienced disease progression before being enrolled in the trial. Patients 1 and 2 independently received three and two courses of infusion, respectively, while patients 3 and 4 received just one course of infusion. Patient 1 exhibited stable disease (SD) for nearly 3 months after adoptive transfer of NY-ESO-1 TCR-T cells based on Response Evaluation Criteria in Solid Tumors (RECIST) 1.1 criteria (Table I). Patient 2 experienced a PR lasting 4 months after treatment. Patients (3 and 4) failed to have an observable clinical response after infusion of TCR-T cells. Adverse events probably related to NY-ESO-1 TCR-T cell therapy in four patients with NSCLC were listed in Table II, and toxicities were graded according to NCI CTCAE version 5.0 (November 27, 2017). All patients experienced transient anemia ( $\leq$ grade 2 ) and white blood cell decrease ( $\leq$ grade 3 ) which were probably induced by the preparative lymphodepleting chemotherapy. These symptoms were relieved after symptomatic treatment, such as granulocyte-colony stimulating factor (G-CSF) infusion and blood transfusion. Three patients exhibited fever (sgrade 3) after administration of IL-2 and recovered upon thermoregulation by themselves or through appropriated treatment. Of note, patient 4 had high fever $\left(40.1^{\circ} \mathrm{C}\right.$, grade 3$)$ that was resolved by oral administration of anti-fever medicine acetaminophen and cessation of IL-2 in one hour. In addition, half of the patients exhibited fatigue, rash, nausea, vomiting and abdominal pain. However, it was difficult to draw general conclusions regarding to the clinical efficacy of anit-NY-ESO-1 TCR-T cells in NSCLC due to the small number of patients enrolled in the present study. Therefore, further clinical investigations with a large number of cancer patients are needed in the future to evaluate the safety and efficacy of anit-NY-ESO-1 TCR-T cell therapy for treatment of lung cancer.

Case report of responding patient. Herein, this study focused on reporting the NY-ESO-1 TCR-T cell treatment in a recruited HLA-A2 positive 44-year-old female patient (patient 2) with metastatic LADC carrying EGFR mutation. Her tumor did not respond to six cycles of combination chemotherapy (docetaxel and carboplatin) in February 2012. In July 2012, she was assessed as having progressive disease (PD) and started to receive treatment with gefitinib for her tumor carrying the EGFR mutation. Computed tomography (CT) scans showed stabilization of her primary lung tumor and liver metastases. However, in January 2015, a surveillance CT scan revealed recurrent disease with new pleural and liver metastases. Treatment was then switched to erlotinib. A follow-up CT scan in September 2015 showed PD in the right pulmonary hilum, mediastinum, right pleura, right hepatic lobe, and liver capsule. There was no central nervous system or skeletal metastases. A bronchoscopic biopsy specimen of the right pulmonary tumor was analyzed by immunohistochemistry and stained strongly for NY-ESO-1 (2+ staining; Fig. 1A). In November 2015, the patient was enrolled in a clinical trial (NCT02457650) assessing autologous T-cell therapy for malignant tumors at the Department of Oncology in Shenzhen Second People's Hospital and the patient provided written informed consent.

A lymphodepleting chemotherapy regimen consisting of CTX (30 mg/ $/ \mathrm{kg} / \mathrm{d}$ for 2 days) and Flud $\left(25 \mathrm{mg} / \mathrm{m}^{2} / \mathrm{d}\right.$ for 3 days) was administrated on the patient 2 before the infusion of NY-ESO-1 TCR-T cells. However, before the first infusion of TCR-T cells, a syndrome of pain and hemoptysis aggravated after she received Flud treatment for one day. For the safety of patient 2, Flud treatment was discontinued for the following two days (Fig. 1B). NY-ESO-1 TCR-T cells $\left(3.07 \times 10^{9}\right.$ total T cells; $2.97 \times 10^{9} \mathrm{TCR}-\mathrm{T}$ cells) were then infused over three days (day 0, 1 and 2) (Fig. 1B). Subsequently, IL-2 was administrated according to the patient's physical condition over six consecutive days (Fig. 1B).

A CT scan obtained in day 43 after the first $\mathrm{T}$ cell infusion revealed regression of the primary lung tumor and 
liver metastases, absorption of hydrothorax and pulmonary re-expansion (Fig. 2A). The primary pulmonary lesion size had reduced from $95 \times 86 \times 54 \mathrm{~mm}$ to $64 \times 44 \times 54 \mathrm{~mm}$. The metastatic liver lesion had also reduced from $19.8 \times 19.6 \times 20 \mathrm{~mm}$ to $10 \times 10 \times 10 \mathrm{~mm}$. The therapeutic effect was assessed as PR according to RECIST 1.1. To further improve treatment efficacy, about one month later, patient 2 received lymphodepleting chemotherapy of CTX $(30 \mathrm{mg} / \mathrm{kg} / \mathrm{d}$ for 2 days) and Flud $\left(25 \mathrm{mg} / \mathrm{m}^{2} / \mathrm{d}\right.$ for 3 days), a second TCR-T cell infusion ( $4.54 \times 10^{9}$ total T cells; $2.87 \times 10^{9} \mathrm{TCR}-\mathrm{T}$ cells) within two days (days 74 and 75), and then IL-2 for eight consecutive days (Fig. 1B). However, the patient's disease had progressed when assessed about two months (day 138) after the second infusion (Fig. 1B). CT scans showed the lung tumor $(94 \times 88 \times 56 \mathrm{~mm})$ and liver metastases $(17.3 \times 16.2 \times 20 \mathrm{~mm})$ had progressed, and the hydrothorax recurred (Fig. 2A). In addition, emission computed tomography (ECT) revealed bone metastases. The efficacy evaluation was PD.

Levels of tumor biomarkers (CEA, CA125, and CA199) were decreased after the initial infusion of TCR-T cells, but later increased. A similar pattern was seen after the second infusion of TCR-T cells targeting NY-ESO-1 (Fig. 2B). The percentage of $\mathrm{CD}^{+} \mathrm{T}$ cells in the peripheral blood of the patient had increased by day 10 after the TCR-T cell infusion, while the percentage of $\mathrm{CD}^{+} \mathrm{T}$ cells was decreased. Furthermore, there was a reduction in the $\mathrm{CD} 8^{+} \mathrm{CD} 28^{-}$subgroup in the blood samples, whereas the percentage of $\mathrm{CD} 4^{+} \mathrm{CD} 25^{+}$in the peripheral blood had increased by 10 days after the T-cell infusion. However, there were no obvious fluctuations in the proportion of $\mathrm{CD} 8^{+} \mathrm{CD} 28^{+}$cell (Fig. $2 \mathrm{C}$ ). Of note, the patient had improvement in Karnofsky performance status (KPS) with a score from 50 to 90 post infusion, and resolution of hemoptysis and chest pain. These results indicate that TCR-T cell treatment has improved the patient's clinical symptoms.

Laboratory assays were conducted to track the persistence of TCR-T cells and examine related immunologic response in vivo. As shown in Fig. 3A, after the first infusion (peak value, 6784.48 copies/ $\mu \mathrm{g}$ DNA), there was a rapid rise in the quantity of TCR DNA copies in the whole blood samples over 2 weeks after the first infusion. This was followed by a rapid decline. Transduced DNA copies of the NY-ESO-1 specific TCR fluctuated between 330.1 and 166.8 copies per $\mu \mathrm{g}$ DNA at 4 weeks. Similar to the first infusion, the DNA copies of NY-ESO-1-specific TCR reached high levels over the second week (peak value, 2362.02 copies $/ \mu \mathrm{g}$ DNA) and then quickly declined over the fourth week after the second TCR-T cell infusion.

Furthermore, patient serum cytokine levels were measured at serial timepoints before and after the cell infusion. IFN- $\gamma$ levels peaked at the second week after cell infusion ( $48.92 \mathrm{pg} / \mathrm{ml}$ post the first infusion, $47.63 \mathrm{pg} / \mathrm{ml}$ post the second infusion) and then gradually degraded to low levels (Fig. 3B). Serum cytokine concentrations of IL-6, IL-10, and granulocyte-macrophage CSF (GM-CSF) displayed little changes (data not shown).

ACT of TCR-T cells was well-tolerated by patient 2 and did not induce clinically apparent cytokine release syndrome (CRS). Although patient 2 had a fever (maximum temperature $39.5^{\circ} \mathrm{C}$, Grade 2) during and after the infusion, it was successfully resolved within three days. In general, there was no

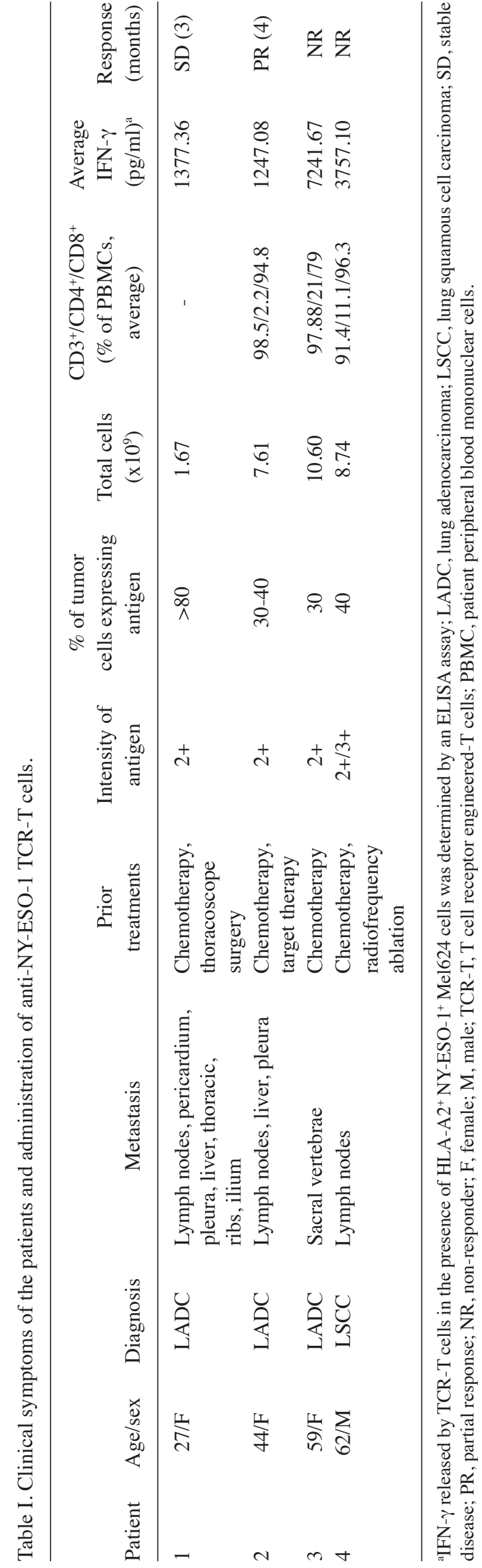


Table II. NY-ESO-1 TCR-T cell therapy-related adverse events in four patients with NSCLC.

\begin{tabular}{|c|c|c|c|c|}
\hline Event & Patient 1 & Patient 2 & Patient 3 & Patient 4 \\
\hline \multicolumn{5}{|c|}{ General disorders and administration site conditions } \\
\hline Chills & - & - & - & $+($ Grade 1$)$ \\
\hline Fatigue & $+($ Grade 1$)$ & - & - & $+($ Grade 1$)$ \\
\hline Fever & $\begin{array}{c}+\left(\leq 38.6^{\circ} \mathrm{C}\right. \\
\text { Grade } 1)\end{array}$ & $\begin{array}{c}+\left(\leq 39.5^{\circ} \mathrm{C}\right. \\
\text { Grade } 2)\end{array}$ & - & $\begin{array}{c}+\left(\leq 40.1^{\circ} \mathrm{C},\right. \\
\text { Grade } 3)\end{array}$ \\
\hline Hyperhidrosis & $+($ Grade 1$)$ & - & - & - \\
\hline \multicolumn{5}{|c|}{ Skin and subcutaneous tissue disorder } \\
\hline Rash & - & $+($ Grade 2$)$ & $+($ Grade 1$)$ & - \\
\hline \multicolumn{5}{|l|}{ Cardiac disorders } \\
\hline Palpitations & - & - & $+($ Grade 1$)$ & - \\
\hline \multicolumn{5}{|l|}{ Gastrointestinal symptoms } \\
\hline Nausea & $+($ Grade 1$)$ & - & $+($ Grade 2$)$ & - \\
\hline Vomiting & - & $+($ Grade 2$)$ & $+($ Grade 2$)$ & - \\
\hline Abdominal pain & - & - & $+($ Grade 1$)$ & $+($ Grade 1$)$ \\
\hline \multicolumn{5}{|c|}{ Blood and lymphatic system disorders } \\
\hline Anemia & $+($ Grade 2$)$ & $+($ Grade 2$)$ & $+($ Grade 1$)$ & $+($ Grade 1$)$ \\
\hline \multicolumn{5}{|l|}{ Investigations } \\
\hline White blood cell decreased & $+($ Grade 3$)$ & $+($ Grade 3$)$ & $+($ Grade 3$)$ & $+($ Grade 2$)$ \\
\hline
\end{tabular}

NSCLC, non small cell lung cancer; TCR-T cells, T cell receptor engineered-T cells.

clinical or laboratory evidences revealing SAEs during TCR-T cell therapy for this patient. However, patient 2 suffered a relapse after the TCR-T cell therapy and thus received six cycles of combination chemotherapy (docetaxel and carboplatin). Notably, she kept taking erlotinib before, during and after the clinical trial. As of October 10, 2017, the patient was still alive with SD.

\section{Discussion}

Cancer-testis antigens, such as MAGE-A3 and NY-ESO-1, are promising candidate targets for cell transfer-based immunotherapies due to their specific expression patterns and strong immunogenicity (19,30,31). MAGE-A3 antigen was previously thought to be a preferred target for immunotherapy of cancers, since its expression had been frequently detected in multiple types of tumors but limited in normal somatic cells $(47,48)$. Nevertheless, adoptive transfer of TCR-T cells targeting MAGE-A3 antigen lead to deaths of two patients due to severe neurological toxicity in recent clinical trials (48). This may due to cross-reactivity of TCR-T cells with MAGE-A12, which is expressed at the low level in the brain tissue (48). In addition, engineered $\mathrm{T}$ cells expressing affinity-enhanced TCRs targeting MAGE-A3 resulted in deaths of the first two patients in another preliminary clinical trial on melanoma and myeloma due to severe cardiac toxicity, which was confirmed by histopathological analysis of the T cell infiltration (47). The following in-depth investigation in vitro shows that the off-target and off-tumor reactivities maybe due to the cross-reactivity of MAGE-A3 TCR-T cells with the human protein titin, which is highly expressed in cardiac tissue $(47,49,50)$.
NY-ESO-1 is one of the best cancer-testis antigens for immunotherapy due to its strong immunogenicity and specific expression pattern. Early study of adoptive transfer of autologous $\mathrm{CD}^{+}{ }^{+} \mathrm{T}$ cells sensitized to NY-ESO-1 peptide in vitro induced tumor regression of metastatic melanoma in 1 of 9 patients (29). Moreover, in a clinical trial conducted by Robbins et al, 11 of 18 HLA-A*0201-positive patients with NY-ESO- $1^{+}$synovial cell sarcomas, and 11 of 20 HLA-A*0201-positive patients with NY-ESO-1 ${ }^{+}$melanoma achieved objective clinical responses following adoptive transfer of NY-ESO-1 TCR-T cells (30). However, one patient with synovial cell sarcomas died three days following the adoptive transfer of NY-ESO-1 TCR-T cells due to septic shock caused by Escherichia coli bacterial infection (30). In another study conducted by Rapoport et al, 16 of 20 patients with myeloma revealed sustained clinical responses following NY-ESO-1 TCR-T cell therapy (31). It was noted that SAEs likely related to treatment, including hypoxia, neutropenia, hyponatremia, hypotension, graft vs. host disease, pancytopenia, and dehydration, were resolved and no treatment related fatalities occurred (31). Meanwhile, no clinically apparent CRS occurred, with the exception of high IL-6 levels (31). By contrast, CRS, which could be potentially life-threatening, was frequently occurred $(93 \%)$ in 94 patients with refractory large B-Cell lymphoma when treated with CAR-T cells targeting CD19 antigen (51). In the present study, although adverse events likely associated with the TCR-T cell treatment also occurred, including anemia, white blood cell decrease, fever, nausea, fatigue and abdominal pain, they were then resolved by symptomatic treatment. Clinically apparent CRS was not observed, despite transiently high IFN- $\gamma$ levels. Meanwhile, there were no treatment-related deaths in 
A

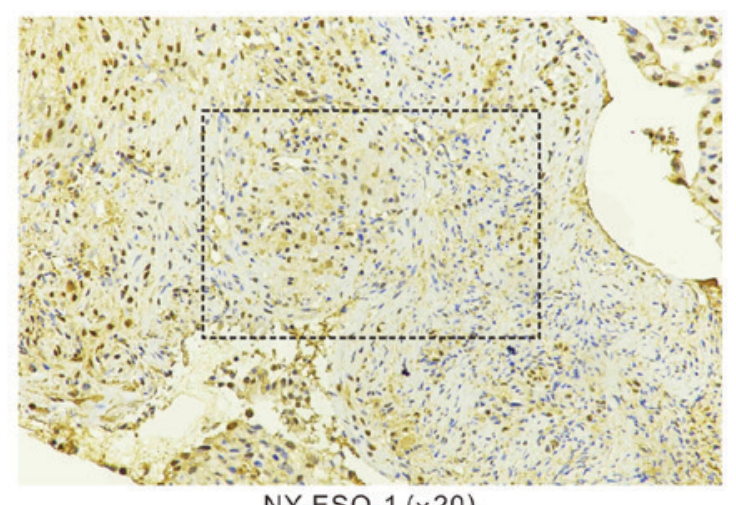

NY-ESO-1 $(\times 20)$

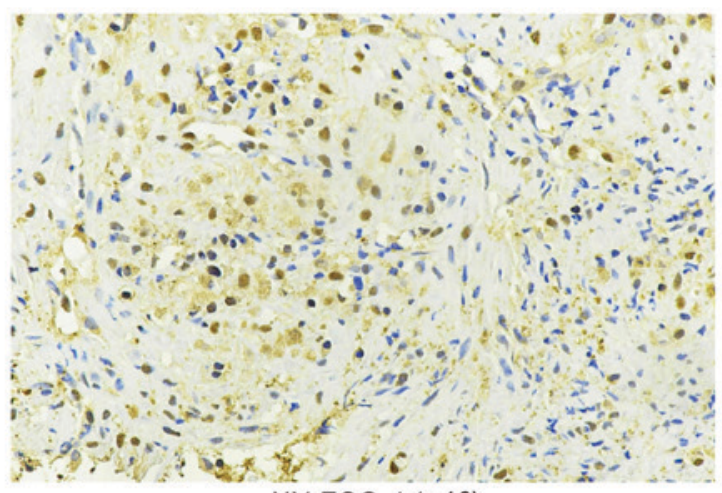

NY-ESO-1 $(\times 40)$

B
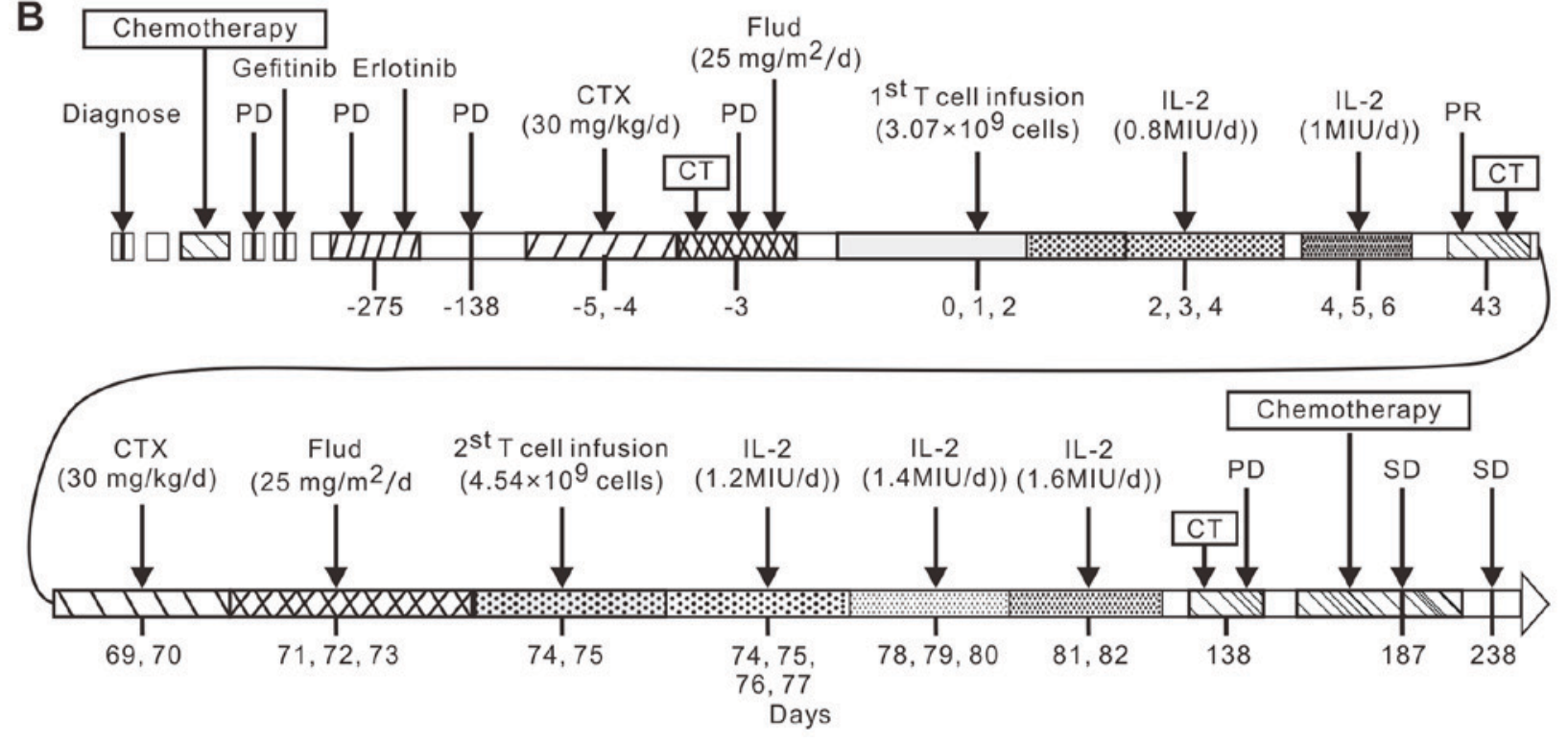

CTX

$\left(25 \mathrm{mg} / \mathrm{m}^{2} / \mathrm{d}\right)$

Figure 1. NY-ESO-1 TCR-T cell therapy treatment schedule for the patient with LADC. (A) Immunohistochemical analysis revealed 3+ staining for NY-ESO-1. (B) The patient was diagnosed with lung adenocarcinoma in February 2012. Her tumor did not respond to six cycles of combination chemotherapy (docetaxel and carboplatin), gefitinib, or erlotinib by September 2015. The patient was then enrolled in the clinical trial (NCT02457650) and received two separate NY-ESO-1-specific TCR-T cell infusions in November 2015 (days 0, 1, and 2) and January 2016 (Day 74, 75). The patient then received another six cycles of chemotherapy (gemcitabine and cisplatin). In addition, the patient took erlotinib throughout the entire trial period. TCR-T, T cell receptor engineered-T cells; LADC, lung adenocarcinoma; CT, computed tomography; PD, progressive disease; SD, stable disease; IL, interleukin; Flud, fludarabine; CTX, cyclophosphamide; PR, partial response.

patients with NSCLC. Taken together, our results show no off-target/off-tumor toxicity and infection. It suggested that NY-ESO-1 TCR-T cell therapy seems to be relatively safe and well-tolerated. Nevertheless, further clinical studies using NY-ESO-1 TCR-T cells in lung cancer and other types of solid tumors are needed in a large number of patients to assess the safety and clinical efficacy of this new treatment.

We showed that treatment with NY-ESO-1 TCR-T cells mediated tumor regression in a patient (1/4) with metastatic NSCLC. Although patient 2 continued to take erlotinib throughout NY-ESO-1 TCR-T cell treatment for her tumor carrying EGFR mutation, it was unlikely that erlotinib played the main part in tumor size reduction, since the patient did not respond to erlotinib alone prior to infusion. Previous study indicated that lymphodepleting chemotherapy regimen and IL-2 administrated to all of the patients may have contributed to the PR in melanoma and/or synovial cell sarcoma patients (30). Nevertheless, we considered that NY-ESO-1 TCR-T cells played a vital role in tumor regression after the first infusion of the TCR-T cells in this case. Firstly, the expression levels of tumor biomarkers (CEA, CA125, and CA199) showed an inverse association with TCR-T cell persistence in the peripheral blood of the patient. This was indicative of the relationship between the curative effect and NY-ESO-1 TCR-T cells. Secondly, IFN- $\gamma$ secretion by CD $4^{+} \mathrm{T}$ cells has been shown to be a potential mechanism underlying the therapeutic effect of tumor-specific CD4 ${ }^{+} \mathrm{T}$ cells in a mouse model bearing B16 melanoma $(52,53)$. The proportion of $\mathrm{CD}^{+} \mathrm{T}$ cells and levels of IFN- $\gamma$ in the peripheral blood were increased after TCR-T cell infusion and were positively correlated with NY-ESO-1 TCR-T cells.

Although patient 2 initially responded well to the ACT with TCR-T cells and achieved PR for nearly 4 months, tumor relapse eventually occurred after the second infusion of TCR-T cells. According to previous studies, several factors may contribute to tumor recurrence after TCR-T cell therapy. Firstly, a loss of persistence and function of genetically-modified $\mathrm{T}$ cells may be associated with tumor relapse $(30,31)$. The persistence of peptide-reactive and tumor-reactive $\mathrm{T}$ cells with MART-1and gp100-recognizing TCRs was positively associated with clinical response (41), while another study showed that relapse was related to the loss of TCR-T cells (31). Therefore, the 
A

Primary site

ydrothorax absorption

Liver
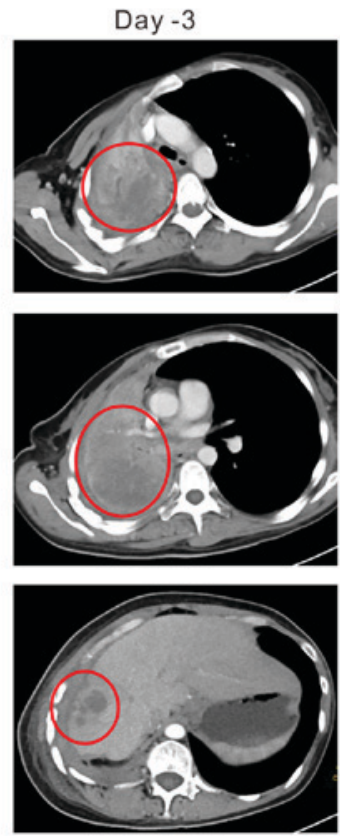

B

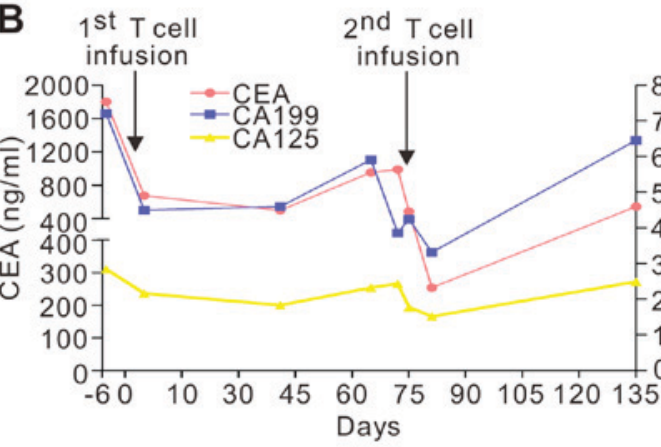

Day 43
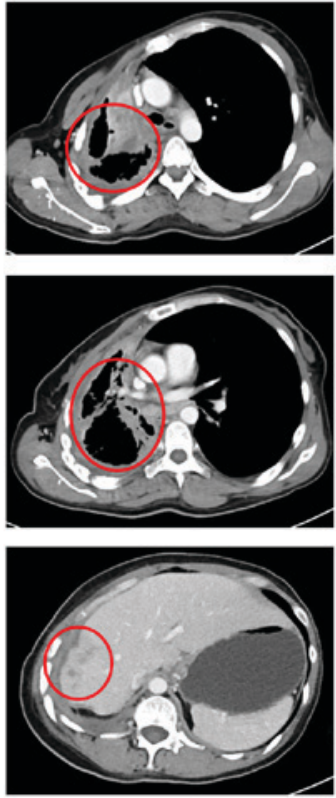

C $\quad{ }^{\text {st }} \mathrm{T}$ cell
Day 138
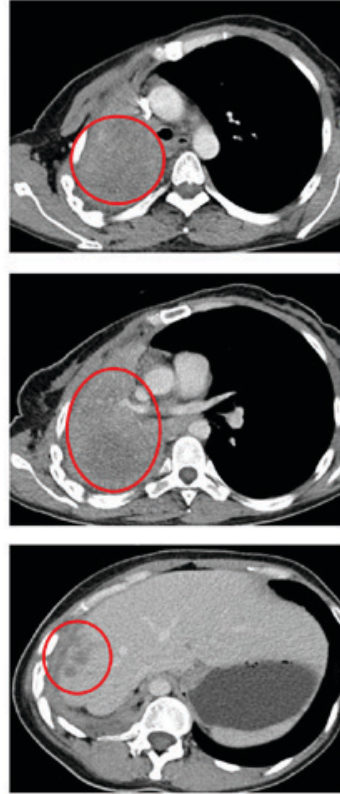

$2^{\text {nd }} T$ cell
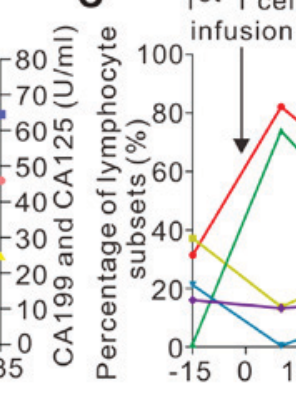

infusion

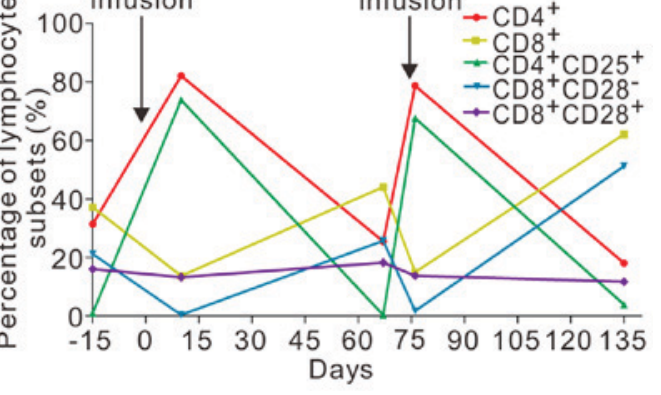

Figure 2. Clinical examination. (A) CT scans revealed a primary tumor located in the right pulmonary hilum with metastases to the mediastinum, right pleura, right hepatic lobe, and liver capsule prior to T cell infusions. In January 2016 (day 43), a CT scan obtained 2 months after the first T-cell infusion showed objective regression of the primary lung tumor and liver metastases, as well as hydrothorax absorption and pulmonary re-expansion. In March 2016 (Day 138), a surveillance CT scan detected growth of the primary lung tumor and liver metastases with re-establishment of the hydrothorax. (B) Levels of the tumor biomarkers (CEA, CA125, and CA199) were reduced 2 weeks post infusion, but then increased 4 weeks after the initial infusion of TCR-T cells. A similar pattern was observed after the second infusion of the NY-ESO-1 TCR engineered T-cells. (C) Proportions of T-cell subsets: Percentages of CD4 ${ }^{+}$and CD8 ${ }^{+} \mathrm{T}$ cells in the peripheral blood of the patient were increased and decreased, respectively, by day 10 after the $\mathrm{T}$ cell infusion. The $\mathrm{CD} 8^{+} \mathrm{CD} 28^{-}$and $\mathrm{CD} 4^{+} \mathrm{CD} 25^{+} \mathrm{T}$ cell subgroups were smaller and larger, respectively, 10 days after the T-cell infusion. There were no obvious changes in the quantity of $\mathrm{CD} 8^{+} \mathrm{CD} 28^{+} \mathrm{T}$ cells. CT, computer tomography; TCR-T, T cell receptor engineered-T cells.
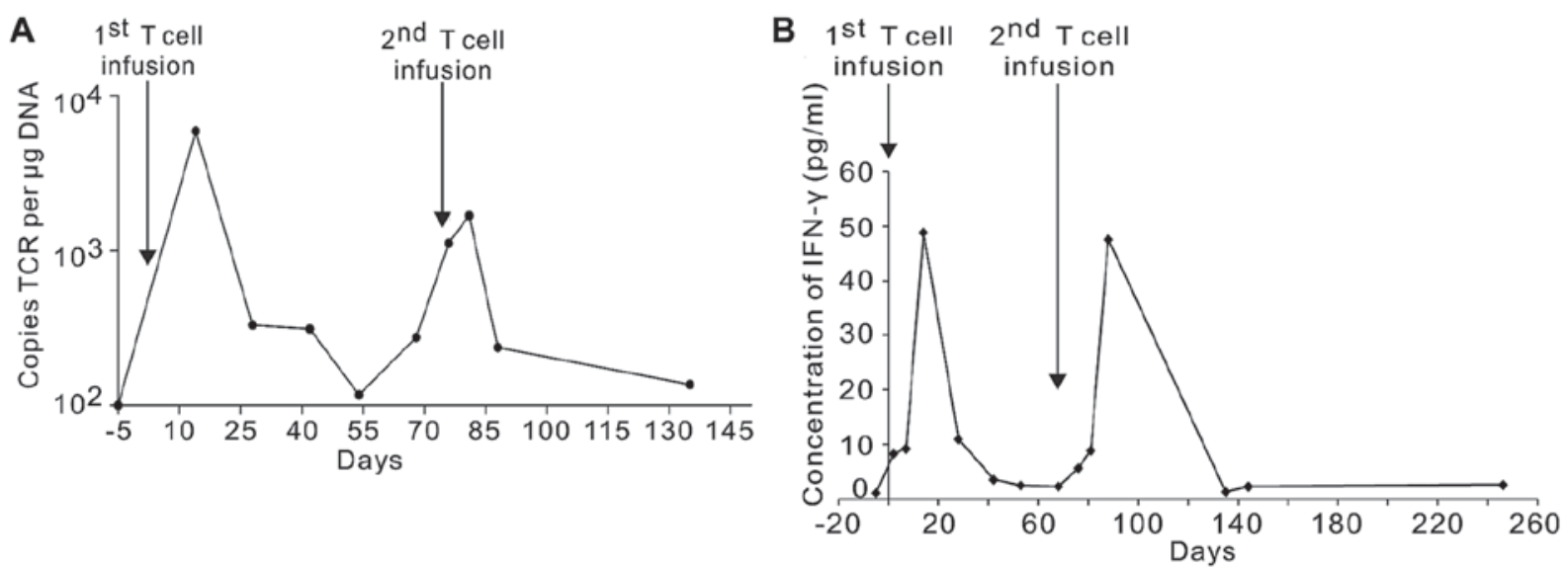

Figure 3. Persistence of NY-ESO-1 TCR-T cells and changes in serum IFN- $\gamma$. (A) Quantitative real-time PCR was used to assess the persistence of NY-ESO-1 TCR-transduced T-cells in vivo. Results are expressed as the copies of TCR clones per $1 \mu \mathrm{g}$ DNA. The modified autologous T lymphocytes were undetectable in pre-infusion samples from the patient (sensitivity of detection of 100 copies $/ \mu \mathrm{g}$ DNA). The quantity of NY-ESO-1 TCR-T cells had rapidly increased in patient blood samples by 2 weeks. However, there was a rapid decrease in the NY-ESO-1 TCR-T cell population by 4 weeks after the first and second T-cell infusions. (B) Concentration of serum IFN- $\gamma$ increased 2-14 days post-infusion and then decreased over the following month. 
approaches to sustain the long-term persistence and function of engineered $\mathrm{T}$ cells in vivo may benefit the durability of the treatment efficacy (31).

Moreover, the antigen expression pattern, such as expression uniformity at diagnosis, loss of target antigen expression, and/or growth of tumor variants lacking expression of the target antigen post-infusion, was one of principal factors that may influence outcome and tumor relapse following treatment with engineered T cells. Compared to the unsatisfying efficacy of TCR-T cells, clinical trials with CAR-T cells targeting B-cell lineage CD19-differentiation antigen demonstrated remarkable clinical efficacy in the induction of long-term stable remission for B-cell malignancies $(17,54,55)$. Notably, unlike CD19 antigen, which is highly and uniformly expressed on B cells, IHC staining of cancer tissues from the patients in studies revealed heterogeneous expression of cancer-testis antigens, such as NY-ESO-1 in the current study.

Furthermore, tumor cells display very strong plasticity, where therapeutic failure and drug resistance may be due to intratumor heterogeneity, which is featured as dynamic genetic diversity and epigenetic plasticity (56). Patients with metastatic melanoma that underwent adoptive transfer of melanocyte antigen-specific $\mathrm{CD}^{+} \mathrm{T}$ cells displayed post-infusion relapse, where residual nodules revealed selective loss of targeted antigens (gp100, tyrosinase, and MART1) in three of the five patients (57). Other studies have shown antigen escape was associated with PD after treatment with NY-ESO-1 and MAGE-A3 TCR-T cells (19,31). Meanwhile, immunotherapy with antigen-specific $\mathrm{T}$ cells has resulted in the outgrowth of antigen-loss tumor variants in some studies $(57,58)$. Suppressive tumor microenvironments expressing inhibitory molecules and receptors, such as PD-1/PD-L1, also contributed to tumor recurrence (59). In the current study, we could not obtain tumor tissue samples for further evaluation after recurrence in the patient 2 due to proximity of the tumor to her right hilus pulmonis. Interestingly, co-treatment with chemotherapy (docetaxel and carboplatin) and erlotinib after treatment with TCR-T cells have controlled disease progression and resulted in SD (as of October 10, 2017).

In summary, immunotherapy with NY-ESO-1 TCR-T cells in four HLA-A2-positive patients with NSCLC is well tolerated without evident severe toxicities. Among the treated patients, the one with advanced LADC revealed a short-term PR (4 months). Although there are some obstacles that need to be overcome for TCR-T cell therapy in solid tumors, such as identification of suitable target antigens, maintenance of persistence and activity of TCR-T cells, enhancement of TCR-T cell trafficking and function, and improvement of tumor microenvironment with immune suppression (59-61), this and other clinical studies in solid tumors strongly suggest that NY-ESO-1 TCR-T cell immunotherapy is relatively safe and well-tolerated. However, further clinical studies are still warranted in a large number of lung cancer patients.

\section{Acknowledgements}

The authors would like to thank Dr Wenlan Liu (The First Affiliated Hospital of Shenzhen University) for support with laboratory instruments.

\section{Funding}

The present study was funded by Shenzhen Peacock Plan (grant no. KQTD20130416114522736); the National Basic Research Program of China (grant no. 2014CB745203), Guangdong Innovative Research Team Program (grant no. 201001Y0104687244), Shenzhen Technology Research Program (grant no. JSGG20160301161836370), Special funds for Dapeng New district industry development (grant nos. KY20150116 and KY20160111) and Natural Science Foundation of Guangdong Province (grant no. 2016A030313238).

\section{Availability of data and materials}

The datasets generated and/or analyzed during the current study are not publicly available due to technology secrecy but are available from the corresponding author on reasonable request.

\section{Authors' contributions}

YX and XT wrote the manuscript, and were responsible for data acquisition, analysis and interpretation; JW, DQ, DB, JC, JY performed TCR-T cell preparation and experimental studies; XL, LX, WL performed clinical studies; MW, GT and RW supervised the entire study, designed the design and approved the protocol. All authors contributed to and approved the final manuscript.

\section{Ethics approval and consent to participate}

The clinical trial (NCT02457650) is registered on ClinicalTrial. gov (https://clinicaltrials.gov/). It was approved by the Medical Ethics Committee of the Institutional Review Board, Shenzhen Second People's Hospital. All procedures performed in studies involving human subjects were in accordance with the ethical standards of the institutional and/or national research committee and with the 1964 Helsinki Declaration and its later amendments or comparable ethical standards. All of the patients enrolled in the trail provided with written informed consent.

\section{Patient consent for publication}

The patient, or parent, guardian or next of kin provided written informed consent for the publication of any associated data and accompanying images.

\section{Competing interests}

The authors declare that they have no competing interests.

\section{References}

1. Siegel RL, Miller KD and Jemal A: Cancer statistics, 2017. CA Cancer J Clin 67: 7-30, 2017.

2. Zarogoulidis K, Zarogoulidis P, Darwiche K, Boutsikou E, Machairiotis N, Tsakiridis K, Katsikogiannis N, Kougioumtzi I, Karapantzos I, Huang H and Spyratos D: Treatment of non-small cell lung cancer (NSCLC). J Thorac Dis 5 (Suppl 4): S389-S396, 2013.

3. Ettinger DS, Wood DE, Aisner DL, Akerley W, Bauman J, Chirieac LR, D'Amico TA, DeCamp MM, Dilling TJ, Dobelbower M, et al: Non-small cell lung cancer, version 5.2017, NCCN clinical practice guidelines in oncology. J Natl Compr Canc Netw 15: 504-535, 2017. 
4. Saito M, Suzuki H, Kono K, Takenoshita S and Kohno T: Treatment of lung adenocarcinoma by molecular-targeted therapy and immunotherapy. Surg Today 48: 1-8, 2018.

5. Larkin J, Chiarion-Sileni V, Gonzalez R, Grob JJ, Cowey CL, Lao CD, Schadendorf D, Dummer R, Smylie M, Rutkowski P, et al: Combined Nivolumab and Ipilimumab or Monotherapy in Untreated Melanoma. N Engl J Med 373: 23-34, 2015.

6. Robert C, Schachter J, Long GV, Arance A, Grob JJ, Mortier L, Daud A, Carlino MS, McNeil C, Lotem M, et al: Pembrolizumab versus Ipilimumab in Advanced Melanoma. N Engl J Med 372: $2521-2532,2015$

7. Kaufman HL, Russell J, Hamid O, Bhatia S, Terheyden P, D'Angelo SP, Shih KC, Lebbé C, Linette GP, Milella M, et al: Avelumab in patients with chemotherapy-refractory metastatic Merkel cell carcinoma: A multicentre, single-group, open-label, phase 2 trial. Lancet Oncol 17: 1374-1385, 2016.

8. Reck M, Rodriguez-Abreu D, Robinson AG, Hui R, Csőszi T, Fülöp A, Gottfried M, Peled N, Tafreshi A, Cuffe S, et al: Pembrolizumab versus chemotherapy for PD-L1-positive non-small-cell lung cancer. N Engl J Med 375: 1823-1833, 2016.

9. Brahmer JR: Immune checkpoint blockade: The hope for immunotherapy as a treatment of lung cancer? Semin Oncol 41: $126-132,2014$

10. Rosenberg SA and Restifo NP: Adoptive cell transfer as personalized immunotherapy for human cancer. Science 348: 62-68, 2015.

11. Stevanovic S, Draper LM, Langhan MM, Campbell TE, Kwong ML, Wunderlich JR, Dudley ME, Yang JC, Sherry RM, Kammula US, et al: Complete regression of metastatic cervical cancer after treatment with human papillomavirus-targeted tumor-infiltrating T cells. J Clin Oncol 33: 1543-1550, 2015

12. Robbins PF, Lu YC, El-Gamil M, Li YF, Gross C, Gartner J, Lin JC, Teer JK, Cliften P, Tycksen E, et al: Mining exomic sequencing data to identify mutated antigens recognized by adoptively transferred tumor-reactive T cells. Nat Med 19: 747-752, 2013

13. San Miguel JF, Paiva B and Lasarte JJ: Engineering anti-myeloma responses using affinity-enhanced TCR-engineered T cells. Cancer Cell 28: 281-283, 2015.

14. Robbins PF, Morgan RA, Feldman SA, Yang JC, Sherry RM, Dudley ME, Wunderlich JR, Nahvi AV, Helman LJ, Mackall CL, et al: Tumor regression in patients with metastatic synovial cell sarcoma and melanoma using genetically engineered lymphocytes reactive with NY-ESO-1. J Clin Oncol 29: 917-924, 2011.

15. Singh H, Huls H, Kebriaei $P$ and Cooper LJ: A new approach to gene therapy using Sleeping Beauty to genetically modify clinical-grade T cells to target CD19. Immunol Rev 257: 181-190, 2014.

16. Porter DL, Levine BL, Kalos M, Bagg A and June CH: Chimeric antigen receptor-modified $\mathrm{T}$ cells in chronic lymphoid leukemia. N Engl J Med 365: 725-733, 2011.

17. Lee DW, Kochenderfer JN, Stetler-Stevenson M, Cui YK, Delbrook C, Feldman SA, Fry TJ, Orentas R, Sabatino M, Shah NN, et al: T cells expressing CD19 chimeric antigen receptors for acute lymphoblastic leukaemia in children and young adults: A phase 1 dose-escalation trial. Lancet 385: 517-528, 2015.

18. Kochenderfer JN, Dudley ME, Kassim SH, Somerville RP, Carpenter RO, Stetler-Stevenson M, Yang JC, Phan GQ, Hughes MS, Sherry RM, et al: Chemotherapy-refractory diffuse large B-cell lymphoma and indolent B-cell malignancies can be effectively treated with autologous T cells expressing an anti-CD19 chimeric antigen receptor. J Clin Oncol 33: 540-549, 2015

19. Lu YC, Parker LL, Lu T, Zheng Z, Toomey MA, White DE, Yao X, Li YF, Robbins PF, Feldman SA, et al: Treatment of patients with metastatic cancer using a major histocompatibility complex class II-restricted T-cell receptor targeting the cancer germline antigen MAGE-A3. J Clin Oncol 35: 3322-3329, 2017.

20. Boon T and Old LJ: Cancer tumor antigens. Curr Opin Immunol 9: 681-683, 1997.

21. Scanlan MJ, Gure AO, Jungbluth AA, Old LJ and Chen YT: Cancer/testis antigens: An expanding family of targets for cancer immunotherapy. Immunol Rev 188: 22-32, 2002.

22. Salmaninejad A, Zamani MR, Pourvahedi M, Golchehre Z, Hosseini Bereshneh A and Rezaei N: Cancer/testis antigens: Expression, regulation, tumor invasion, and use in immunotherapy of cancers. Immunol Invest 45: 619-640, 2016.

23. Stockert E, Jäger E, Chen YT, Scanlan MJ, Gout I, Karbach J, Arand M, Knuth A and Old LJ: A survey of the humoral immune response of cancer patients to a panel of human tumor antigens. J Exp Med 187: 1349-1354, 1998.
24. Maio M, Coral S, Sigalotti L, Elisei R, Romei C, Rossi G, Cortini E, Colizzi F, Fenzi G, Altomonte M, et al: Analysis of cancer/testis antigens in sporadic medullary thyroid carcinoma: Expression and humoral response to NY-ESO-1. J Clin Endocrinol Metab 88: 748-754, 2003.

25. Scanlan MJ, Altorki NK, Gure AO, Williamson B, Jungbluth A, Chen YT and Old LJ: Expression of cancer-testis antigens in lung cancer: Definition of bromodomain testis-specific gene (BRDT) as a new CT gene, CT9. Cancer Lett 150: 155-164, 2000.

26. Scanlan MJ, Gout I, Gordon CM, Williamson B, Stockert E, Gure AO, Jäger D, Chen YT, Mackay A, O'Hare MJ and Old LJ: Humoral immunity to human breast cancer: antigen definition and quantitative analysis of mRNA expression. Cancer Immun 1: 4, 2001.

27. Chen YT: The journey from autologous typing to SEREX, NY-ESO-1 and cancer/testis antigens. Cancer Immun 12: 8, 2012

28. Jager E, Chen YT, Drijfhout JW, Karbach J, Ringhoffer M, Jäger D, Arand M, Wada H, Noguchi Y, Stockert E, et al: Simultaneous humoral and cellular immune response against cancer-testis antigen NY-ESO-1: Definition of human histocompatibility leukocyte antigen (HLA)-A2-binding peptide epitopes. J Exp Med 187: 265-270, 1998.

29. Hunder NN, Wallen H, Cao J, Hendricks DW, Reilly JZ, Rodmyre R, Jungbluth A, Gnjatic S, Thompson JA and Yee C: Treatment of metastatic melanoma with autologous CD4+ T cells against NY-ESO-1. N Engl J Med 358: 2698-2703, 2008.

30. Robbins PF, Kassim SH, Tran TL, Crystal JS, Morgan RA, Feldman SA, Yang JC, Dudley ME, Wunderlich JR, Sherry RM, et al: A pilot trial using lymphocytes genetically engineered with an NY-ESO-1-reactive T-cell receptor: Long-term follow-up and correlates with response. Clin Cancer Res 21: 1019-1027, 2015 .

31. Rapoport AP, Stadtmauer EA, Binder-Scholl GK, Goloubeva O, Vogl DT, Lacey SF, Badros AZ, Garfall A, Weiss B, Finklestein J, et al: NY-ESO-1-specific TCR-engineered T cells mediate sustained antigen-specific antitumor effects in myeloma. Nat Med 21: 914-921, 2015.

32. Kim SH, Lee S, Lee CH, Lee MK, Kim YD, Shin DH, Choi KU, Kim JY, Park DY and Sol MY: Expression of cancer-testis antigens MAGE-A3/6 and NY-ESO-1 in non-small-cell lung carcinomas and their relationship with immune cell infiltration. Lung 187: 401-411, 2009.

33. Gjerstorff MF, Pøhl M, Olsen KE and Ditzel HJ: Analysis of GAGE, NY-ESO-1 and SP17 cancer/testis antigen expression in early stage non-small cell lung carcinoma. BMC Cancer 13: 466, 2013.

34. Oshima Y, Shimada H, Yajima S, Nanami T, Matsushita K, Nomura F, Kainuma O, Takiguchi N, Soda H, Ueda T, et al: NY-ESO-1 autoantibody as a tumor-specific biomarker for esophageal cancer: Screening in 1969 patients with various cancers. J Gastroenterol 51: 30-34, 2016

35. Tureci O, Mack U, Luxemburger U, Heinen H, Krummenauer F, Sester M, Sester U, Sybrecht GW and Sahin U: Humoral immune responses of lung cancer patients against tumor antigen NY-ESO-1. Cancer Lett 236: 64-71, 2006.

36. Laport GG, Levine BL, Stadtmauer EA, Schuster SJ, Luger SM, Grupp S, Bunin N, Strobl FJ, Cotte J, Zheng Z, et al: Adoptive transfer of costimulated $T$ cells induces lymphocytosis in patients with relapsed/refractory non-Hodgkin lymphoma following CD34+-selected hematopoietic cell transplantation. Blood 102: 2004-2013, 2003

37. Rapoport AP, Stadtmauer EA, Aqui N, Badros A, Cotte J, Chrisley L, Veloso E, Zheng Z, Westphal S, Mair R, et al: Restoration of immunity in lymphopenic individuals with cancer by vaccination and adoptive T-cell transfer. Nat Med 11: 1230-1237, 2005.

38. Klebanoff CA, Khong HT, Antony PA, Palmer DC and Restifo NP: Sinks, suppressors and antigen presenters: How lymphodepletion enhances $\mathrm{T}$ cell-mediated tumor immunotherapy. Trends Immunol 26: 111-117, 2005.

39. Robson NC, McAlpine T, Knights AJ, Schnurr M, Shin A, Chen W, Maraskovsky E and Cebon J: Processing and cross-presentation of individual HLA-A, -B, or -C epitopes from NY-ESO-1 or an HLA-A epitope for Melan-A differ according to the mode of antigen delivery. Blood 116: 218-225, 2010.

40. Robbins PF, Li YF, El-Gamil M, Zhao Y, Wargo JA, Zheng Z, $\mathrm{Xu}$ H, Morgan RA, Feldman SA, Johnson LA, et al: Single and dual amino acid substitutions in TCR CDRs can enhance antigen-specific T cell functions. J Immunol 180: 6116-6131, 2008 . 
41. Johnson LA, Morgan RA, Dudley ME, Cassard L, Yang JC, Hughes MS, Kammula US, Royal RE, Sherry RM, Wunderlich JR, et al: Gene therapy with human and mouse T-cell receptors mediates cancer regression and targets normal tissues expressing cognate antigen. Blood 114: 535-546, 2009.

42. Hughes MS, Yu YY, Dudley ME, Zheng Z, Robbins PF, Li Y, Wunderlich J, Hawley RG, Moayeri M, Rosenberg SA and Morgan RA: Transfer of a TCR gene derived from a patient with a marked antitumor response conveys highly active T-cell effector functions. Hum Gene Ther 16: 457-472, 2005.

43. Topalian SL, Solomon D and Rosenberg SA: Tumor-specific cytolysis by lymphocytes infiltrating human melanomas. J Immunol 142: 3714-3725, 1989.

44. Maude SL, Frey N, Shaw PA, Aplenc R, Barrett DM, Bunin NJ, Chew A, Gonzalez VE, Zheng Z, Lacey SF, et al: Chimeric antigen receptor $\mathrm{T}$ cells for sustained remissions in leukemia. $\mathrm{N}$ Engl J Med 371: 1507-1517, 2014.

45. Kalos M, Levine BL, Porter DL, Katz S, Grupp SA, Bagg A and June $\mathrm{CH}$ : $\mathrm{T}$ cells with chimeric antigen receptors have potent antitumor effects and can establish memory in patients with advanced leukemia. Sci Transl Med 3: 95ra73, 2011.

46. Livak KJ and Schmittgen TD: Analysis of relative gene expression data using real-time quantitative PCR and the 2(-Delta Delta C(T)) method. Methods 25: 402-408, 2001.

47. Linette GP, Stadtmauer EA, Maus MV, Rapoport AP, Levine BL, Emery L, Litzky L, Bagg A, Carreno BM, Cimino PJ, et al: Cardiovascular toxicity and titin cross-reactivity of affinity-enhanced $\mathrm{T}$ cells in myeloma and melanoma. Blood 122 863-871, 2013

48. Morgan RA, Chinnasamy N, Abate-Daga D, Gros A, Robbins PF, Zheng Z, Dudley ME, Feldman SA, Yang JC, Sherry RM, et al: Cancer regression and neurological toxicity following anti-MAGE-A3 TCR gene therapy. J Immunother 36: 133-151, 2013.

49. LeWinter MM and Granzier H: Cardiac titin: A multifunctional giant. Circulation 121: 2137-2145, 2010.

50. Herman DS, Lam L, Taylor MR, Wang L, Teekakirikul P, Christodoulou D, Conner L, DePalma SR, McDonough B, Sparks E, et al: Truncations of titin causing dilated cardiomyopathy. N Engl J Med 366: 619-628, 2012.

51. Neelapu SS, Locke FL, Bartlett NL, Lekakis LJ, Miklos DB, Jacobson CA, Braunschweig I, Oluwole OO, Siddiqi T, Lin Y, et al: Axicabtagene Ciloleucel CAR T-Cell Therapy in Refractory Large B-Cell Lymphoma. N Engl J Med 377: 2531-2544, 2017.
52. Muranski P, Boni A, Antony PA, Cassard L, Irvine KR, Kaiser A, Paulos CM, Palmer DC, Touloukian CE, Ptak K, et al: Tumor-specific Th17-polarized cells eradicate large established melanoma. Blood 112: 362-373, 2008

53. Quezada SA, Simpson TR, Peggs KS, Merghoub T, Vider J, Fan X, Blasberg R, Yagita H, Muranski P, Antony PA, et al: Tumor-reactive CD4(+) T cells develop cytotoxic activity and eradicate large established melanoma after transfer into lymphopenic hosts. J Exp Med 207: 637-650, 2010.

54. Wei G, Ding L, Wang J, Hu Y and Huang H: Advances of CD19-directed chimeric antigen receptor-modified T cells in refractory/relapsed acute lymphoblastic leukemia. Exp Hematol Oncol 6: 10, 2017.

55. Tasian SK and Gardner RA: CD19-redirected chimeric antigen receptor-modified T cells: A promising immunotherapy for children and adults with B-cell acute lymphoblastic leukemia (ALL). Ther Adv Hematol 6: 228-241, 2015.

56. Greaves M: Evolutionary determinants of cancer. Cancer Discov 5: 806-820, 2015.

57. Yee C, Thompson JA, Byrd D, Riddell SR, Roche P, Celis E and Greenberg PD: Adoptive T cell therapy using antigen-specific CD8+ T cell clones for the treatment of patients with metastatic melanoma: In vivo persistence, migration and antitumor effect of transferred T cells. Proc Natl Acad Sci USA 99: 16168-16173, 2002.

58. Mackensen A, Meidenbauer N, Vogl S, Laumer M, Berger J and Andreesen R: Phase I study of adoptive T-cell therapy using antigen-specific CD8+ T cells for the treatment of patients with metastatic melanoma. J Clin Oncol 24: 5060-5069, 2006.

59. Hay KA and Turtle CJ: Chimeric antigen receptor (CAR) T cells: Lessons learned from targeting of CD19 in B-cell malignancies. Drugs 77: 237-245, 2017.

60. Irving M, Vuillefroy de Silly R, Scholten K, Dilek N and Coukos G: Engineering chimeric antigen receptor T-cells for racing in solid tumors: Don't forget the fuel. Front Immunol 8: 267, 2017.

61. Frigault MJ and Maus MV: Chimeric antigen receptor-modified T cells strike back. Int Immunol 28: 355-363, 2016.

This work is licensed under a Creative Commons

Attribution-NonCommercial-NoDerivatives 4.0 International (CC BY-NC-ND 4.0) License. 